\title{
Direct Gas Chromatographic Analysis of Molasses and Fermented Mash ${ }^{1}$
}

\author{
Eduardo Rosado and H. Batiz ${ }^{2}$
}

\begin{abstract}
A gas chromatographic system of a $118 \mathrm{ft} \times 1 / 8$ in o.d. stainless steel column of $5 \%$ Carbowax $^{3}$ 20M and Chromosorb W, a/w 60/80 mesh, a glass precolumn 6 in $\times 1 / 8$ in o.d. with the same stationary phase and an external dismountable injection trap was constructed and pretested for the direct analysis of fermented mash. Thirty four peaks were detected of which 14 were identified. This technique can be applied to analysis of slops or similar mixtures with suspended solids.
\end{abstract}

\section{INTRODUCTION}

Sugarcane molasses is the raw material used for the production of rum by yeast fermentation. In this process ethyl alcohol is produced, as well as other substances, many of which are distilled together with the ethyl alcohol when the mash is distilled. These other substances in rum are known as rum congeners. In order to obtain a good distillate it is necessary to control the quantities of congeners in the distillate. Gas-liquid chromatography has proved to be a good technique for studying the mash composition and the formation of components during fermentation.

A gas chromatographic method for the analysis of major congeners ${ }^{4}$ was developed at the Rum Pilot Plant. It has been used for fermented mash analysis, with fractional distillation of the fermented mash prior to analysis. Most of the congeners heavier than ethyl alcohol are partially removed. Yokota et al. ${ }^{5}$ developed another method for the analysis of volatile components of cane molasses. At least 35 components of cane molasses were detected by gas chromatography of which 29 were

${ }^{1}$ Manuscript submitted to Editorial Board May 11, 1975.

${ }^{2}$ Research Chemist and Chemist, respectively. Agricultural Experiment Station, Mayagüez Campus, University of Puerto Rico, Río Piedras, P.R.

${ }^{3}$ Trade names are used in this publication solely for the purpose of providing specific information. Mention of a trade name does not constitute a guarantee or warranty of equipment or materials by the Agricultural Experiment Station of the University of Puerto Rico or an endorsement over other equipment or materials not mentioned.

${ }^{4}$ Manual de métodos analíticos de la planta piloto de ron, Rum Pilot Plant, Agricultural Experiment Station, University of Puerto Rico, Río Piedras, P.R., 1969.

${ }^{5}$ Yokota, M., and Fagerson, I. S., J. Food Sci., 36: 1091-4, 1971. 
identified. The procedure used is complex and could lead to unreliable recovery.

A different method for rapid and direct gas chromatographic analysis of esters, acetal, aldehydes, and fusel alcohol in the unfermented and fermented mash is under development at this station. Preliminary results are presented.

\section{MATERIAL AND METHODS}

Puerto Rican cane molasses was fermented in the usual manner. ${ }^{6}$ About $15 \mathrm{ml}$ fermented mash was centrifuged $15 \mathrm{~min}$ at $3,500 \mathrm{r} / \mathrm{m}$ to remove part of the suspended solids. The supernatant was transferred to a vial and sealed. Seventy five $\mathrm{ml}$ of fermented mash without centrifugation were distilled following the same procedure used for the determination of alcohol in the fermented mash. ${ }^{6}$ The distillate, the centrifuged residue of the distillation, and the fermented mash were kept for analysis.

A Hewlett-Packard 5750 gas chromatograph was used with the injection system modified as in figure 1. The external trap (d) retains solids; then the small glass precolumn (f) traps smaller solids of high boiling point and high polarity that may have passed.

To connect the external trap, a modification was made of the carrier gas line of the chromatograph oven. The three-way valve (c) was connected between the carrier flow valve (b) and the injection port (e). The three-way valve has two outlets, one going to line (i) and the other to line (j). When the trap is operating, line (i) is open and line (j) is closed. When the trap is disconnected, the carrier flow is reversed from line (i) to line (j). Carrier lines (i) and (j) must be provided with 0.01 in i.d. tubing to avoid backflush of the carrier gas, which may produce undesirable peaks on the chromatogram.

The sample is injected and flash evaporated in the dismountable trap given in figure 2 , where most of the solids are retained. To remove the solids the trap is provided with a stainless steel tubing $(\mathrm{m})$ plugged with fiberglass which has to be replaced before injection of a different sample. The trap is covered with a heating tape and the temperature is controlled with a variable powerstat. The glass precolumn is connected between the injection port (e) and the main column (g) with Teflon ferrules (fig 1). This precolumn has the same diameter as the main column and must be replaced when a brown stain is visible on the absorbent.

In order to carry out the analysis, the chromatograph was set to the conditions described in table 1 . The temperature of the oven was increased to the upper limit and the trap connected in the proper

${ }^{6}$ Manual de métodos y procedimientos bacteriológicos de la planta piloto de ron, Agricultural Experiment Station, University of Puerto Rico, Río Piedras, P.R., 1969. 


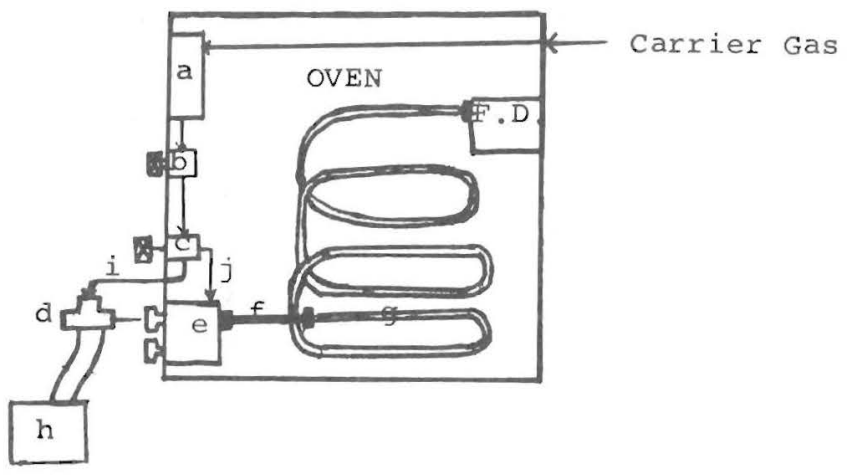

FIG. 1.-System used in direct analyses; $a$, carrier flow meter; $b$, carrier flow valve; $c$, 3 -way valve; $d$, dismountable external trap; e, injection port; f, glass precolumn 6 in $\times 1 / 8$ in o.d. of $5 \%$ Carbowax $20 \mathrm{M}$, acid washed, and 60/80 mesh Chromosorb W; g, stainless steel column $18 \mathrm{ft} \times 1 / 8$ in o.d. of $5 \%$ Carbowax $20 \mathrm{M}$, acid washed, and 60/80 mesh Chromosorb W; h, Voltobox a.c. power supply; i, Teflon tubing 1/8 in o.d.; j, injection port stainless steel tubing.

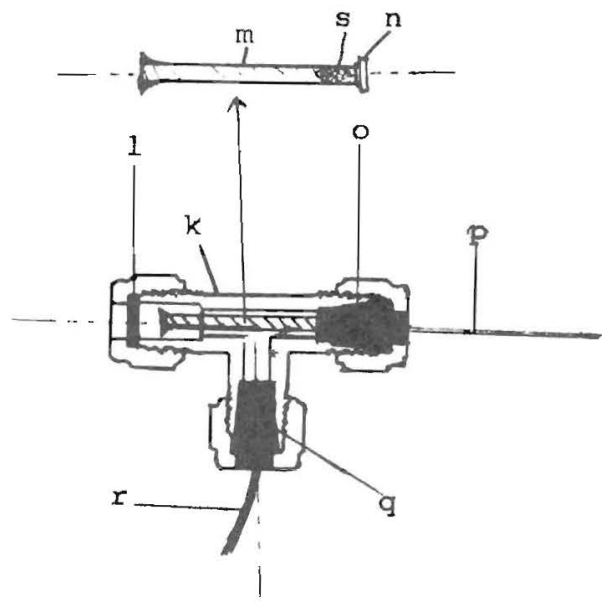

Fig. 2,-Cross-section of external trap; $k$, stainless steel T-union $1 / 4$ in o.d.; 1 , septum $m$, stainless steel tubing $3 / 8$ in $\times 1 / 8$ in o.d.; $n$, stainless steel back ferrule $1 / 8$ in o.d.; o, Teflon terrule reducer $1 / 4$ to $1 / 16$ in o.d.; p, stainless steel needle no. 19; q, Teflon ferrule reducer $1 / 4$ to $1 / 16$ in o.d.; r, Teflon tubing $1 / 16$ in o.d.; s, Fiberglass filter.

position. The system was cleaned by injecting $3 \mu \mathrm{l}$ of water in the external trap, and after the base line remained constant, cooling the oven to $50^{\circ} \mathrm{C}$. Immediately a $3 \mu \mathrm{l}$ sample was injected and the programmer set in order to attain the temperatures as in table 1 . The temperature was kept constant at the upper limit until no additional peaks appeared in the chromatogram (about $40 \mathrm{~min}$ after injection). The whole system was 
TABLE 1.-Conditions for the chromatographic analysis

\begin{tabular}{ll}
\hline Post Injection interval & $4 \mathrm{~min}$ \\
Temperature program & $15^{\circ} \mathrm{C} / \mathrm{min}$ \\
Upper limit interval & $0 \mathrm{~min}$ \\
Lower limit temperature & $60^{\circ} \mathrm{C}$ \\
Upper limit temperature & $140^{\circ} \mathrm{C}$ \\
Programmer selector & Recycle \\
Oven cover & Automatic \\
Trap temperature & $200^{\circ} \mathrm{C}$ \\
Injection port temperature & $170^{\circ} \mathrm{C}$ \\
Flame detector temperature & $170^{\circ} \mathrm{C}$ \\
Carrier gas & $\mathrm{Helium}$ \\
End column carrier flow & $19 \mathrm{ml} / \mathrm{min}$ at $40 \mathrm{lb} / \mathrm{in}^{2}$ \\
Air rotameter & 2.5 \\
Hydrogen rotameter & 2.0 \\
\hline
\end{tabular}

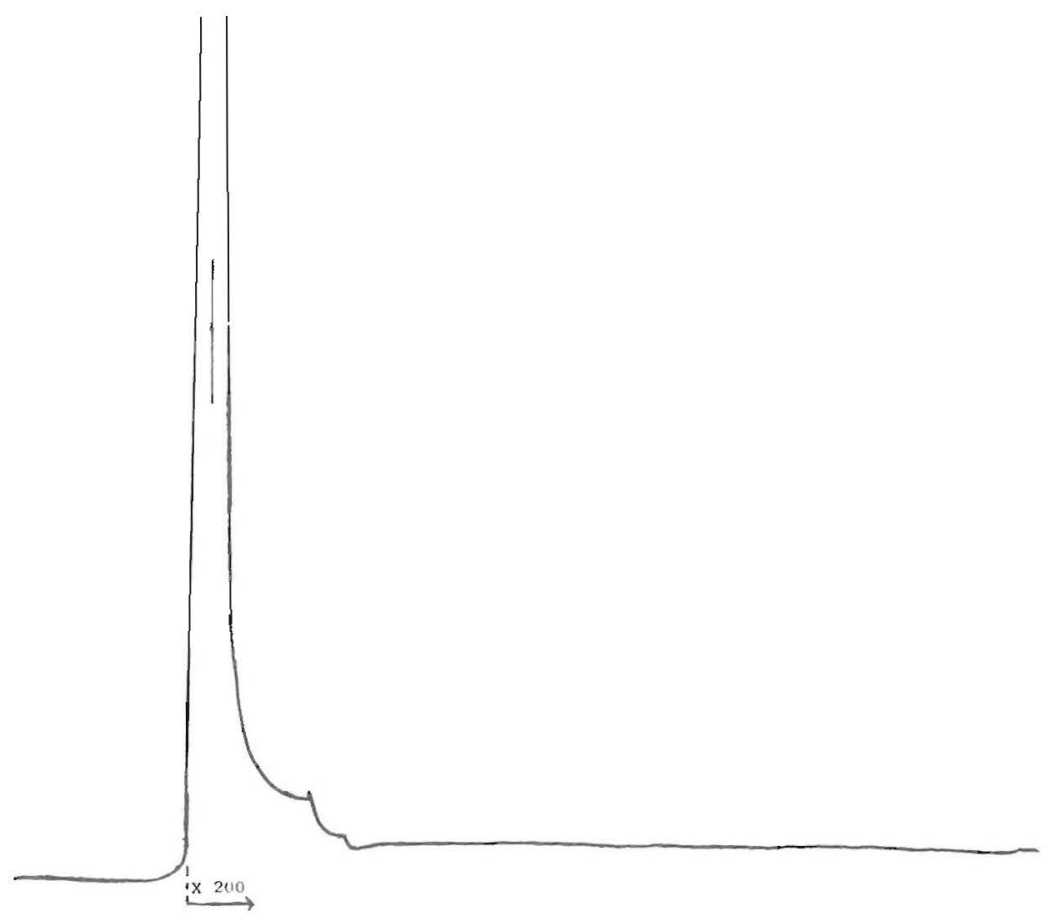

Fig. 3,A.-Gas Chromatograph of $3 \mu \mathrm{l}$ of ethyl alcohol $20^{\circ} \mathrm{P}$.

flushed again with water to start another injection of the same sample for a duplicate analysis. This is necessary because small amounts of the components are retained in the system which interfere with subsequent 
chromatograms. After going through the above-mentioned procedure, and before another sample was injected, the trap was removed and cleaned thoroughly.

To clean the trap, the oven is set at the upper temperature limit. The carrier flow is changed from (i) to line (j) (fig. 1) and the trap disconnected, cooled, the insert cleaned or replaced, and the trap restored. The carrier gas is then allowed in the line (i). The water flushing is repeated, and the system is ready for a new sample.

Figures 3,A, 3, B, 3, C, and 3,D present qualitative analyses of a $20^{\circ} \mathrm{P}$ ethyl alcohol solution; a representative fermented mash, its distillate, and the residue of its distillation. Identification of components was made by comparing retention times of the components in the fermented mash with retention times of the pure compound in a reference solution in ethyl alcohol $20^{\circ} \mathrm{P}$.

\section{RESULTS AND DISCUSSION}

There are 33 more signals in the chromatogram of the fermented mash (fig. 3,B) than in the one of ethyl alcohol $20^{\circ} \mathrm{P}$ (fig. 3,A), of which 14 of these were identified. The first 11 peaks are usually separated and

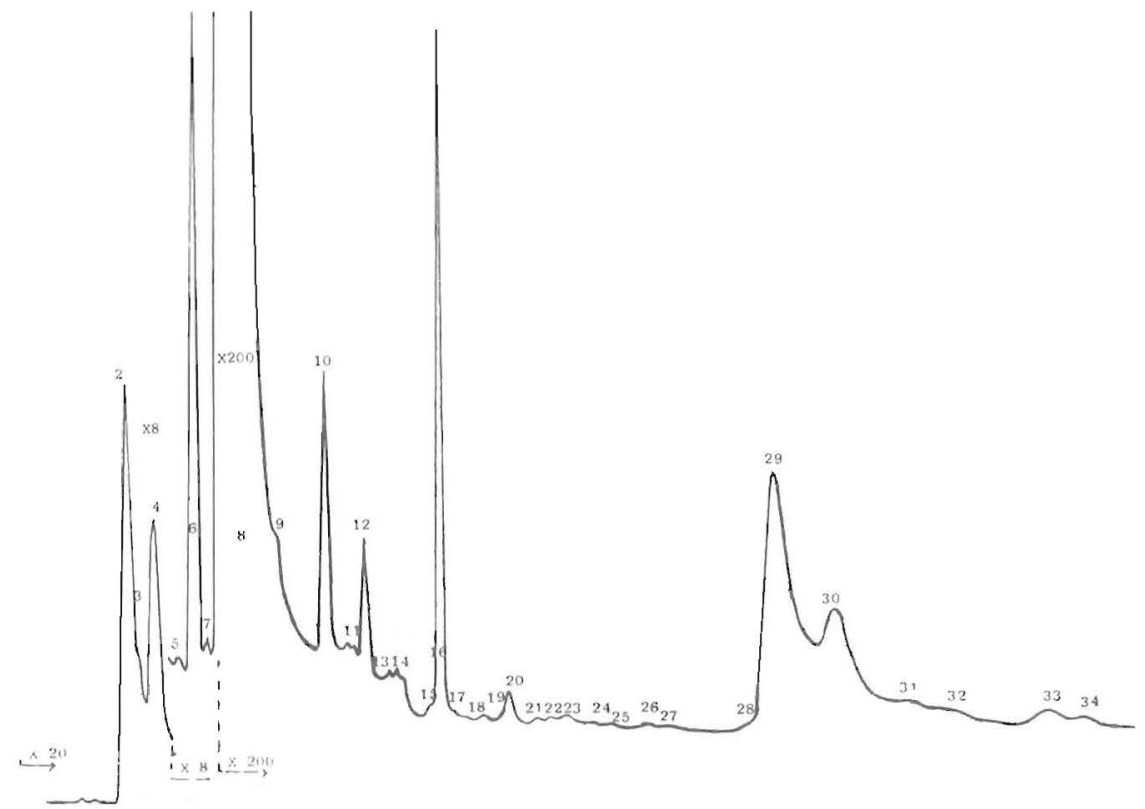

FIG. 3,B.-Gas Chromatograph of a $3 \mu$ I fermented mash. 2, acetaldehyde; 4, ethyl acetate; 6 , methyl acetate; 7 , acetal; 8 , ethyl alcohol; 10, n-propyl alcohol; 12, isobutyl alcohol; 13, isoamyl acetate; 14, butyl alcohol; 16, isoamyl alcohol; 18, amyl alcohol; 26 , furfuraldehyde; 29, fulfuryl acetate; 34 , fulfuryl alcohol. 


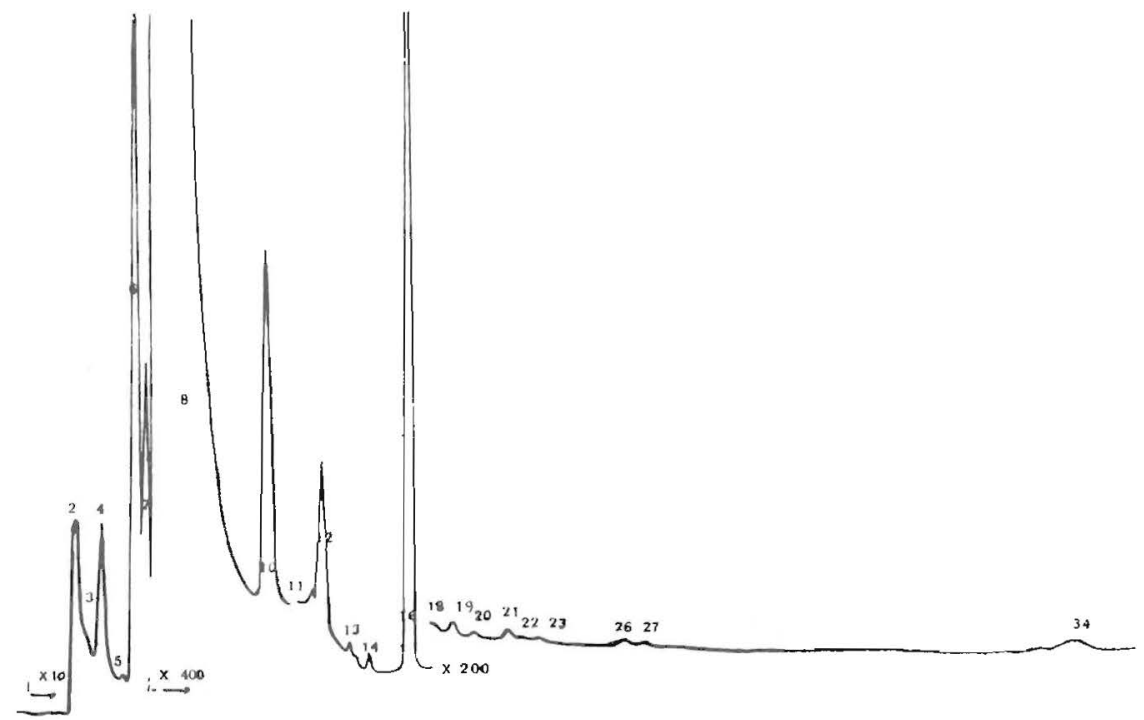

Fig. 3,C.-Cas Chromatograph of $3 \mu \mathrm{l}$ of distillate of fermented mash. 2, acetaldehyde; 4, ethyl acetate; 6 , methyl acetate; 7 , acetal; 8 , ethyl alcohol; 10 , n-propyl alcohol; 12 , isoamyl acetate; 13 , n-butyl alcohol; 14, butyl alcohol; 16, isoamyl alcohol; 18, amyl alcohol; 26 , furfuraldehyde; 34 , fulfuryl alcohol.

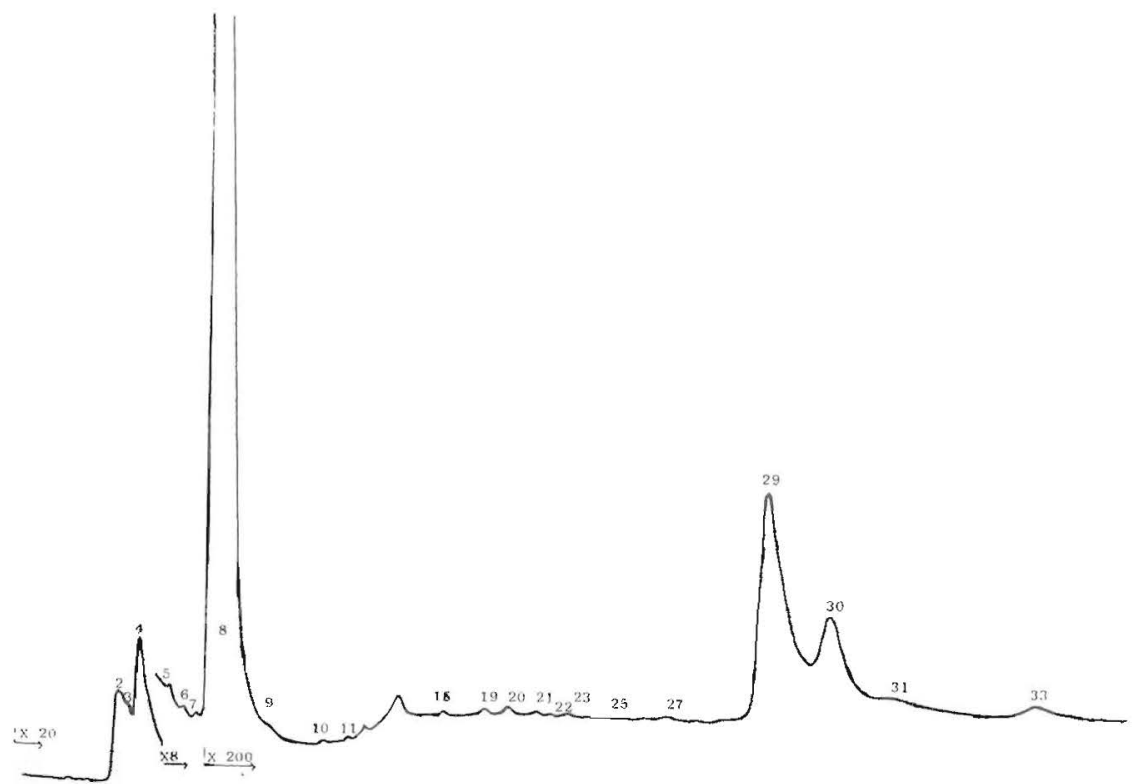

FIG. 3,D.-Gas Chromatograph of $3 \mu \mathrm{l}$ centrifuged residue after distillation of fermented mash (slop). 2, acetaldehyde; 4 , ethyl acetate; 6 , methyl acetate; 7 , acetal; 8 , ethyl alcohol; 10, n-propyl alcohol; 16 , isoamyl alcohol; 29, fulfuryl acetate. 
identified as major congeners of rum ${ }^{4}$. Furfural was also analyzed by ultraviolet spectrophotometry ${ }^{4}$. Furfural and fulfuryl alcohol also have been reported in molasses by Yokota ${ }^{5}$.

The qualitative data showed an incomplete distillation of fermented mash before analysis, since the chromatogram of the distillate (fig. 3,C) had fewer signals than that of the fermented mash (fig. 3,B) or the residue (fig. 3,D). The signals in the chromatograms belonging to heavy components in the residue are about the same size as in the fermented mash, which show that little distillation of these components occurred.

\section{RESUMEN}

Para el análisis directo de melazas fermentadas, se construyó un sistema cromatográfico consistente de una columna de acero inoxidable de 18 pies por $1 / 8$ de pulgada de diámetro exterior, con Carbowax $20 \mathrm{M}$ al $5 \%$ en Chromosorb W, lavado en ácido y tamizado en una malla 60/80; una precolumna de cristal de 6 pulgadas por $1 / 8$ de pulgada de diámetro exterior, con la misma fase estacionaria; y un inyector externo, desmontable. En el análisis preliminar se detectaron 34 señales cromatográficas, de las cuales 14 fueron identificadas. Esta técnica puede aplicarse al análisis de mostos o mezclas similares que contengan sólidos suspendidos. 